\title{
PLENARY LECTURE: THE TEACHING OF STATISTICS IN MOROCCO L'ENSEIGNEMENT DE LA STATISTIQUE AU MAROC
}

\author{
Adil El Marhoum \\ University Mohammed V Rabat, Faculty of Legal, Economic and Social Sciences, Morocco \\ adil.elmarhoum@gmail.com
}

Discussing higher education in Morocco, particularly about statistics, the talk reflects on the following points:

- Interest of statistics

- $\quad$ Place of statistics in education programs in Morocco

- Difficulties in teaching statistics

- $\quad$ Teachers of statistics and teaching methods

- $\quad$ Suggestions for further increasing the penetration of statistics into curricula

Various reforms of Moroccan education have consistently placed more emphasis on the teaching of statistics. This teaching is currently being introduced in most of the training streams, such as economics, management sciences, and agronomic sciences. Despite this positive development, there are a number of shortcomings in the teaching of statistics. There is an absence of statistical reasoning in students: the ability to analyze and interpret the results of calculations. Statistics courses are taught by teachers who have often been forced to teach it, usually mathematics teachers, who on the whole have a formal approach to statistics. The mathematician takes the place of the statistician, without considering more applied questions. In order to encourage better statistical understanding, we suggest the presence of experienced statisticians in any university or scientific research institution, in association if necessary; training seminars (Study visits, refresher courses, thematic networking of statisticians, etc.) in countries with more statistics education capacity; local training for researchers; participation in regional seminars; creation of courses of study more oriented towards statistical processing and data processing; and drafting and dissemination of guides to good statistical practice in experimentation, sampling and publication of results. 